\title{
Digital twins: development and implementation challenges within Moroccan context
}

\author{
Mezzour Ghita ${ }^{1,2}$ (D) $\cdot$ Benhadou Siham ${ }^{1,2} \cdot$ Medromi Hicham $^{1,2} \cdot$ Aitelmahjoub Abdelhafid $^{3} \cdot$ Deshayes Laurent $^{4}$
}

Received: 21 October 2019 / Accepted: 4 April 2020 / Published online: 11 April 2020

(c) Springer Nature Switzerland AG 2020

\begin{abstract}
Industrial world today is experiencing its fourth industrial revolution. Predecessor of the automation industry, Industry-4.0 adds a layer of autonomy, intelligence and advanced connectivity to complex industrial systems. This layer creates an interactive and dynamic bridge between virtual systems and physical systems with their upward constraints and requirements in a constantly changing physical environment. Digital twins fall into the category of advanced concepts and technologies that enhance this connectivity. Several projects have been launched in Morocco by the government, industrialists and research communities, initiating the digital transformation of Moroccan industrial manufactories and companies. This paper comes within this framework, firstly to highlight the great potential that digital twins can offer for Moroccan industrial context enhancement, secondly to identify the challenges that can hinder the integration and development of digital twins in Moroccan industrial environment.
\end{abstract}

Keywords Digital twins · Industry 4.0 · Digital twins' challenges and opportunities · Moroccan industrial context

\section{Introduction}

Today Moroccan industrial tissue and all its agents and different operational and strategic components are confronted to an acute dilemma. This dilemma that obliges industrials and country's agents to revolutionize their practices has emerged consequently to the introduction of the fourth industrial revolution throughout the world. A revolution initiated by the development of communication and information technologies, and their integration within manufacturing plants [1], and as a result to the launching of digital transformation across Morocco as key strategic step towards an economic and scientific transformation reinforced in the last few years. Firstly, by the promotion of innovation, and scientific and technical creativity throughout the country [2], secondly with the implementation of several projects targeting the integration of innovative digital solutions within all Moroccan dynamic ecosystems [3]. This dilemma for industrial ecosystems in particular revolves around the improvement of two major dimensions.

The first dimension focuses on revolutionizing manufactories hardware and software infrastructures. The second-dimension relays on the evolvement of existing approaches and methodologies for manufacturing operations monitoring.

A lot of concepts inspired by proposed models for industry 4.0 integration can help Moroccan ecosystems to deal with these dilemmas.

Mezzour Ghita, mezzzourghita1@gmail.com; Benhadou Siham, benhadou.siham@gmail.com; Medromi Hicham, Hmedromi@yahoo.fr; Aitelmahjoub Abdelhafid, aitelmajoub@gmail.com; Deshayes Laurent, Deshayes.laurent@um6p.ma | ${ }^{1}$ Engineering Research Laboratory (LRI), System Architecture Team (EAS), National and High School of Electricity and Mechanic (ENSEM), Hassan II University Casablanca, Casablanca, Morocco. ${ }^{2}$ Research Foundation for Development and Innovation in Science and Engineering, 8118 Casablanca, Morocco. ${ }^{3}$ L.I.S.S.I.E.E ENSAM, Hassan II University Casablanca, Casablanca, Morocco. ${ }^{4}$ ILO, Polytechnic University of Mohammed VI, Benguerir, Morocco. 
Among concepts that were introduced to industrial plants under the auspices of industry 4.0 is digital twin concept [4]. Digital twin consists on the development of virtual replicas that result from the fusion and interconnection between cyber and physical systems.

Since its apparition digital twin concept has been representing several scientific and technological challenges [5]. These challenges at first were mainly related to the concept understanding, definition, development and deployment within different physical environments. A few years later due to the concept expansion its challenges differed and increased from one context to another due to numerous criteria. These criteria were essentially associated to digital twins proposed architectures deployment within physical environments of complex systems. Thus its consisted on the enhancement of existing hardware and software infrastructures, enterprises data management techniques and strategies, and last but not least digital twins implemented solutions features and services [6]. As a result to digital twin multiscale dimension, and due to its implementation process complexity, and multidisciplinary the success of digital twins development and deployment projects in worldwide level and particularly for this paper in Morocco is strongly linked to the handling of different challenges that can revolve from its deployment attempt.

This paper main purpose is to identify and discuss digital twins' development and deployment threats and opportunities within Morocco. The first section of the paper set forth a state of the art on digital twin concept development and identifies its research challenges throughout literature. The second section introduces a survey conducted within Morocco concerning digital twin, and its recognition within the context. Firstly, in relationship to industry 4.0 technologies and applications, secondly as an independent concept and its potential of application, implementation challenges and opportunities. The third section represents survey results synthesis and analysis, and finally the last section opens on future research axes and perspectives.

\section{State of art}

\subsection{Concept development}

Digital twin concept hasn't seen its appearance with the fourth industrial revolution crossing the door of manufactories. It first introduction to both scientific and industrial communities goes back well before the initiation of industry 4.0 [7]. Several bibliographical sources linked the concept evolvement to Dr. Grieves. Dr Grieves who is best known for his research advances in the field of Product Lifecycle Management (PLM) [8]. Dr Grieves at one of his lectures given at the University of Michigan in 2003 initiated the possibility of creating a virtual system that would be the twin of complex physical mechatronic system, and communicate with it continuously for applications related to PLM, predictive maintenance and complex industrial systems manufacturing [9].

A few years later through his book on complex systems and the evolution of PLM Grieves introduced publicly the term digital twin [10].

Although Grieves' name was linked in several articles to the emergence of the concept, the notion of complex systems twin has emerged at first with the National Aeronautics and Space Administration NASA Apollo program, and in the aerospace and military fields that are particularly critical in terms of complex systems manufacturing [11].

Alongside NASA, US air force, which exploited the concept in the same sector also presented several detailed researches on the subject while introducing new concepts such as Digital Thread [12]. US Air Force with a detailed study on digital twin application for weapon systems development proved the necessity to create a design road map and ecosystem for digital twin development and implementation. Throughout this roadmap they highlighted some of digital twins main challenges and requirements mainly hardware and software infrastructures, and labor force required competencies [13]. After several years of in-depth research in the field of virtual modeling, simulation techniques, data analysis and visualization, and since the evolution of information and communications technologies digital twins saw their applications extended to several fields. Some of these fields are chiefly maintenance and product health management PHM [14], realtime monitoring [15], ergonomics [16], education [17], production systems management [18], smart grids [19], energy efficiency and more recently healthcare [20]. This multidisciplinary aspect that the concept acquired as a result of its exploitation for numerous and completely different purposes, and due to its combination with multiple concepts and technologies that included some of digital transformation major actors such as augmented reality, big data and industrial internet of things (IIOT) [21], new requirements and criteria were added for its successful implementation within industrial plants. The concept extension and application in different fields reinforced its three-layered architecture proposed initially by Grieves.

Thus, recent research on the subject defined it through five layers. The first layer consists on the physical system 
and its physical environment, the second layer introduces the virtual system and its virtual environment, whereas the third layer is constituted through cyber physical communication, and finally the fourth layer relays on the two systems data management components. And finally the last layer is services layer [22].

While analyzing digital twins' applications and different results and obstacles they have known for their efficient integration, and throughout the five layers framework assessment in a worldwide context, and with a context independent perception we were able to identify some of digital twin development and deployment ecosystem components in relationship with industry 4.0 and digital transformation. Some of these components concerned concept development architectures and linked it to other concepts for example real time simulation and cyber physical systems development $[23$, p. 0$]$, and others concerned its implementation constraints that mainly discuss communication infrastructures, virtual and physical data exchange, processing techniques, and finally labor force capabilities [24].

Turning back from the worldwide context to a contextual vision, in recent years a lot of Moroccan scientific communities have been working to support the deployment of industry 4.0 technologies within Moroccan landscape. This support consisted on the implementation of projects that favor creativity, and the development of solutions created by Morocco's actors and adapted to the specific constraints of the Moroccan context. Many sectors have benefited from these efforts. These efforts aimed at first changing and digitizing several processes including public services and administrations [25] which are currently the subject of several digitization projects, education sector with the introduction of E-learning techniques [26], and last but not least smart cities concept [27] with initiatives such as Casablanca Smart city project [28] which has been strengthened over the last years by the organization of conferences and the launch of national and international workshops, researches, and national and international surveys. Among the sectors that are also making great strides in this revolution within Morocco is renewable energies sector especially solar energy. Solar energy is a key asset of the kingdom which both industrial and scientific communities are trying to develop though the building of adaptive and homemade smart and advanced solutions.

One of the concepts promoted by platform 4.0 vision and that have been exploited by Moroccan companies lately is Big data for the capitalization of knowledge across industrial companies [29], and predictive analysis for applications in public administration [30]. Cloud computing, Internet of Things [31], Smart Cities applications [32], and finally artificial intelligence which is in full swing through the launch of several calls for projects by various private and public organizations and institutions essentially the government [33] are all strategic axis that Morocco is working on recently in order to integer efficiently the fourth industrial revolution.

Alongside these various projects a lot of researches have been launched to strengthen and assist the integration of industry 4.0. These researches have been focusing on cyber security management, human capital management, IT market needs management [34], the improvement of national infrastructures in the field of ICT's, and several other areas that enable the creation of Morocco's platform 4.0 and its components of which today digital twin is a key elements according to several international assessments [35].

\subsection{Research challenges and digital thread concept}

Most of researches related to digital twin before industry 4.0 dealt with issues specific to its development and requirements. For example, digital twin architecture reliability in representing its real compatriot within the field, its effectiveness, Cyber physical connectivity and communication, digital twin technologies potential for different fields of application, and topics that relates to the concept itself. We cite mainly its definition, its development and its link with other concepts that could lighten its development process, the type of communication that would allow it to maintain real time and optimized connection with its physical twins, as well as its related environment. Other researches dealt with computing capabilities required by its software infrastructure to accurately represent the functioning of its physical twin [36]. Lately some research groups discussed issues related to digital twins' technologies energy efficiency [37], and several other problems involving several domains including mechanics, electrical engineering, automation and real time reactivity.

Industry 4.0 has made a significant contribution to the evolvement of digital twins. With the evolution of modelling techniques for cyber physical systems, the improvement of computing capacities and simulation software's performances, the introduction of machine learning through industrial application, and a lot of others evolutions that has enabled digital twin to overcome a part of its implementation challenges [38], and controversy raised new problematics that can help digital twins potential to be fully exploited within manufactories.

One of the crucial issues that were discussed through literature and among industrial communities is digital twins' efficient implementation within the field when 
it concerns legacy systems, and the challenges and requirements that could hinder this integration. One of the research groups that discussed this problem is US Air Force research community. Through researches launched the group of study concluded that digital twin's development and deployment project success is strongly related to the establishment of a national change management strategy that compels the commitment of all project stakeholders. Morocco through its different research communities and industrial ecosystems is entering the new era of digitization. This entrance is fostered through enterprises whole supply chain, and by the development of digital transformation framework throughout the country. These two elements that can benefit digital twins' integration within Morocco. Researches made in the field of digital twins encourage enterprises horizontal and vertical integration. This integration that consists on creating enterprise internal synergies, and external collaboration with its environment [39]. Morocco industrial agents, public institutions, and research organisms are trying hand in hand to reinforce this vision by the development of ICT tools and infrastructures [40], and through improving learning techniques and management approaches conformity to national and international market needs and new technologies requirements.

\subsection{Aim of the study}

The main purpose of this study is to define a Road Map for the development and deployment of sustainable and efficient digital twins within Moroccan industrial context. Through the literature review of the concept we were able to conclude that a decisive step in digital twins' life cycle management is the in depth analysis of the physical environment where it will be implemented, and the different agents that the twin will communicate with whether it is project stakeholders or involved legacy systems. Thus, the survey main purposes are to:

- Identify the perception of digital twin concept among Moroccan scientific and industrial communities.

- Identify main risks and obstacles that could hinder the adoption of the concept.

- Identify the main challenges that can results from the deployment of the concept in the Moroccan context.

- Identify principal challenges within physical environments with which the twin will have to communicate.

- Elaborate global and relevant evaluation criteria on which Moroccan research communities can rely in order to define different measures and guidelines to be taken for the efficient deployment of digital twins within Moroccan industrial ecosystems.

\section{Materials and methods}

\subsection{Sampling}

Literature review on digital twin concept development and use cases of worldwide application within industrial environments enabled us to identify a set of stakeholders that can contribute to digital twins' development and deployment within Moroccan context. The result of these studies highlighted three different categories.

The first category concerns groups of researchers interested in the development of new advanced concepts and technologies within Moroccan context, and research communities that have already worked on the deployment of one of industry 4.0 concepts through Moroccan industrial tissue. These communities are in direct contact with scientific advances regarding industry 4.0. Through their experience feedback acquired from the implementation of advanced technologies within Moroccan context these two communities can help us to highlight potential risks and opportunities offered by the development of Morocco's digital twins.

The second category includes three communities. The first community within this category is constituted by manufacturers who operate in the development of advanced industry 4.0 solutions, work on their implementation within industrial plants, and have their subsidiaries in Morocco. The second community is comprised of companies that have developed a digital transformation road map. Finally, the last community in this category is of industrial companies that have already integrated digital technologies into their production plants, and that have developed their own active research and development branches within Morocco.

The last categories are formed by Moroccan startups that work for the development of new innovative and technological solutions, and startups that operate in the support of Moroccan enterprises on their digitalization journey. Figure 1 represents survey sample and Figs. 2, 3, and 4 describe industrial communities characteristics.

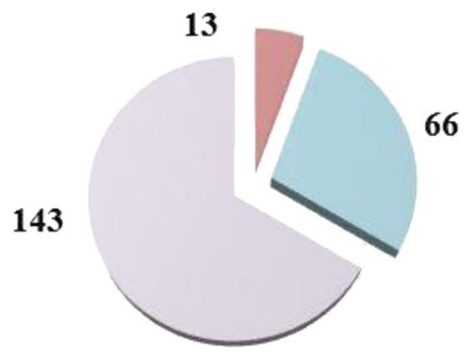

Start up

Research community Industrial community

Fig. 1 Survey sample 


\section{Industrial community}

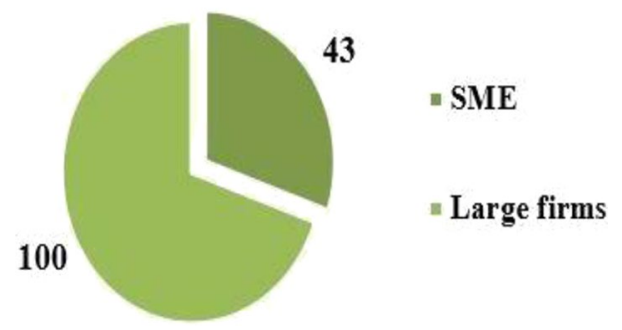

Fig. 2 Industrial community characteristics

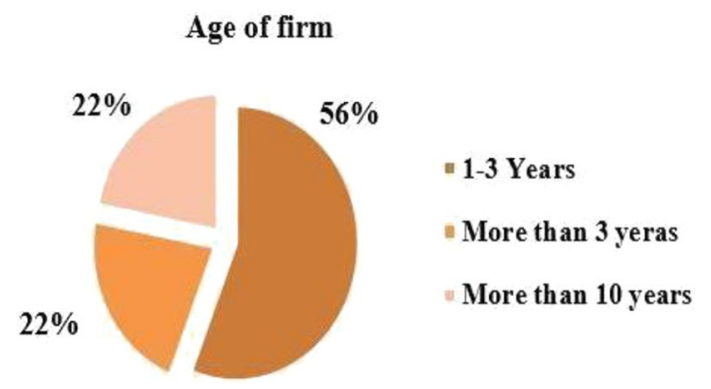

Fig. 3 Age of sample firms

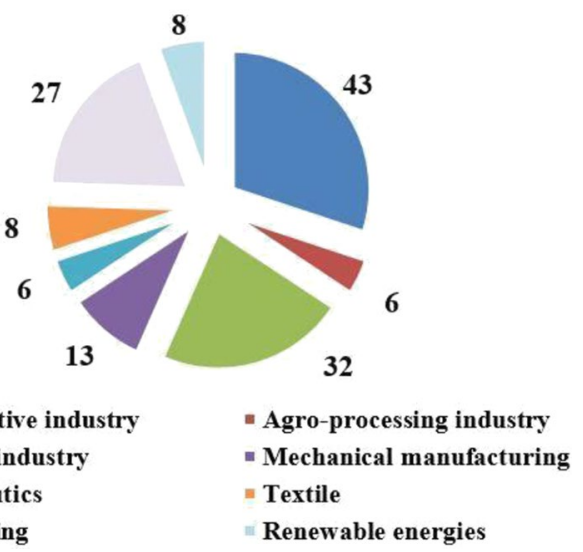

Fig. 4 Sectors of activity

\subsection{Method}

Concept development analysis, its fields of application, its proposed architectures for development and deployment throughout literature, and the analysis of Moroccan context feedback on the application of digitalization across the results of national and international reports allowed us to detect some obstacles that could hinder the development and implementation of digital twin technologies in the Moroccan industrial environment, and the opportunities and potential development axes that could in the contrary foster its integration. These analysis results were summarized through the paper by the establishment of strength, weaknesses, opportunities, and threats (SWOT) analysis on the subject. SWOT analysis point out on the one hand the internal factors that can foster the concept implementation regarding different aspects. These aspects focused on digital twin development architecture, Moroccan enterprises key strengths and weaknesses, and industrial environment and national environment main current axes of development. On the other hand, the presented SWOT analysis underlines firstly, the different opportunities offered by external and international context, secondly the external threats that can hinder digital twin deployment within Moroccan industrial ecosystems. Digital transformation integration through Morocco has revolutionized a lot of fields' mainly renewable energies, public services and public administration, urban mobility, and last but not least education. In recent years a lot of joint ventures and project were launched to foster this integration across the different fields we stated above. The creation of public platforms by the government for the promotion of data exchange [41], innovative ideas gathering [25], and the implementation of universities dedicated to research and development like Polytechnic University of Mohammed VI (UM6P) and Research Foundation for Development and Innovation in Science and Engineering (FRDISI) has helped Moroccan country to make great advances in terms of digitalization. Recent national reports and studies highlighted the impact of these efforts on Morocco's digital transformation and the different challenges that the country must deal with furtherly [42]. The analysis on the one hand of the results presented in these studies and the results presented in previous studies conducted by international organizations [43], and on the other hand our state of the art on digital twins, and the challenges surrounding them that have been explored by researchers and manufacturers since their appearance have allowed us to develop the SWOT analysis that was presented in this paper and survey main sections that will be detailed further (Table 1). Figure 1 summarizes SWOT analysis for digital twins' implementation within Moroccan industrial context (Fig. 5).

The survey focused on three main axes, the elaboration of the questions as well as the definitions and visions provided by the survey were based on previous studies results conducted within Morocco, and the state of the art on digital twins.

The first axis dealt with questions around industry-4.0 in Moroccan context in general. All that relates to its perceptiveness, interviewed sample perception regarding its proposed different technologies which could represent potential solutions for problematics encountered by both scientific and industrial communities. The objective behind this axis was first to identify based on 
Table 1 Survey set of questions

Survey set of questions

Q1 Which definition seems to you to be the closest to the perception of industry 4.0 in the Moroccan context?

An industrial revolution focused on artificial intelligence and the Internet of Things

Smart, autonomous and connected plants

An ecosystem of several advanced technologies working in synergy to improve plants performances

A set of good and innovative practices and methods to integrate the evolution of information and communication technologies in industry but also in several other fields

Smart cities, smart factories, smart devices

Q2 In Morocco, which field of application do you think is most likely to benefit from the advances of industry 4.0?

Education towards E-learning

Transport and urban logistics towards intelligent mobility

Product life management PLM

Product health management PHM

Other

Q3 What is the industry 4.0 concept according to you that can easily find a place in a Moroccan industrial context?

Artificial intelligence

Machine learning

Augmented and virtual reality

Robotics and autonomous robots

Big data

Digital twins

Internet of Things

Block chain

Q4 According to degrees of importance, what are the most relevant criteria for you when choosing a 4.0 solution (based on a ranking from 1 most important to 6)

Energy consumption regards

Investment in equipment, training required in comparison with the return on investment of the project as a whole

Development and implementation of the solution costs and delays

Adaptability and interoperability with current organization systems

Feedback on the solution in similar contexts

Existence of certification or national or international laws organizing the development and deployment of the solution

What could prevent your adoption of a 4.0 solution such as digital twins?

Resistance to change of employees

High development and deployment costs

The return on investment is sustainable in the long term

The need to train or recruit new employees

The lack of mastery of these new concepts

Security and confidentiality risks

Q6 Which definition seems closest to your understanding of digital twins

A virtual representation of a real system that allows a real time visualization of the system's operation and performance

Advanced simulation technology

A dynamic representation of a complex system in a virtual environment with advanced computing and processing capabilities

Q7 What technology do you think is most related to digital twins?

Big data

Internet of Things loT

Augmented reality and virtual reality

Cloud computing

Q8 Do you adopt a digital twin technology in your office?

Yes

No

Under development

In the process of implementation

Q9 Do you have an ERP system?

Yes

No

Under development

In the process of implementation 
Table 1 (continued)

Survey set of questions

Q10 Do you have a Manufacturing Execution System MES?

Yes

No

Under development

In the process of implementation

Q11 On a scale of 5 how will you evaluate the performance of the information systems offered by the Moroccan market?

1 non-performing

2 not very efficient

3 meet requirements and needs

4 efficient

5 mature

Q12 On a scale of 5 how will you evaluate the performance of the database management systems proposed by the Moroccan market?

1 non-performing

2 not very efficient

3 meet requirements and needs

4 efficient

5 mature

Q13 Are you for or against storage in the cloud?

For

Against

For with conditions

Q14 Your requirements for cloud storage

Q15 Between private cloud and public cloud, you choose

You do not yet understand the difference and characteristics of the two

Private

Public

interviewed sample point of view digital twin concept position among other industry- 4.0 concepts, and then through this to detect potential and most relevant fields of application for digital twins among industrialist and researchers. The second part of the survey addressed

\begin{tabular}{|c|c|}
\hline $\begin{array}{l}\text { Strengths } \\
\text { - Moroccan strategy oriented towards the digitalization } \\
\text { and use of manufacturing } 4.0 \text { concepts } \\
\text { Emergence of many research and development } \\
\text { organizations at the service of industry } 4.0 \\
\text { development and deployment } \\
\text { - Creation of Moroccan digital development agency and } \\
\text { data sharing and gathering platforms } \\
\text { - Emergence of several Start UPs whose core business is } \\
\text { the development of innovation and advanced } \\
\text { technologies related to industry } 4.0 \\
\text { Development of a training center or master's degree in } \\
\text { digital transformation, artificial intelligence (UM6P, } \\
\text { OCP, and FES University)..... } \\
\text { - Liability at the level of the new finance law for the } \\
\text { financing of Start UP by large companies }\end{array}$ & $\begin{array}{l}\text { Opportunities } \\
\text { - Several studies carried out } \\
\text { by experts for the evaluation } \\
\text { of digital maturity in } \\
\text { developing countries } \\
\text { Existence of several } \\
\text { Moroccan subsidiaries or } \\
\text { partnerships with leading } \\
\text { companies in digital } \\
\text { technologies (Deloitte, } \\
\text { Siemens, Schneider, IBM, } \\
\text { etc.) }\end{array}$ \\
\hline $\begin{array}{l}\text { Weaknesses } \\
\text { - Resilience to change by some of the stakeholders } \\
\text { - Concerns about cyber security and the return on } \\
\text { investment } \\
\text { - High costs of integration and more infrastructure } \\
\text { adaptation costs } \\
\text { - Resistance to public data sharing including operational } \\
\text { data sharing } \\
\text { - Lack of updates for websites and platforms that are } \\
\text { dedicated to data sharing } \\
\text { - Infrascture poorly adapted to fulfill the requirements } \\
\text { of advanced digital technologies integration }\end{array}$ & $\begin{array}{l}\text { Threats } \\
\text { - Increasing intemational } \\
\text { requirements in digital and } \\
\text { emerging technologies } \\
\text { - Need to improve the digital } \\
\text { maturity of all industrial } \\
\text { ecosystem not only large } \\
\text { companies } \\
\text { - Limited and highly } \\
\text { restricted access to scientific } \\
\text { international reports and } \\
\text { data bases }\end{array}$ \\
\hline
\end{tabular}

exclusively digital twin concept, including its definition, fields of application, different evaluation criteria according to its possible stakeholders, risks that could hinder its deployment, its relationship with other technologies that are proposed by industry 4.0, and finally its current status within Moroccan plants and industrial sectors. This part questions were developed based on our literature review and state of the art on the concept, and its different requirements concluded while analyzing use cases of application within different contexts and fields [43]. The third section of the survey focused on the adaptability of the current environment to meet digital twin development and implementation basic requirements. We were able to identify these requirements through the study of experience feedback of different existing use cases of developed and implemented digital twin technologies, and through the analysis of research results that were published by Moroccan scientific communities concerning the implementation and integration of the fourth industrial revolution within Moroccan country. This section of the survey was concerned with two aspects. The first one is physical infrastructure and data processing management infrastructures, mainly management of

Fig. 5 SWOT analysis for digital twins within Morocco 
manufacturing operations legacy systems MOM and integrated systems including enterprise resource planning proposed software. And the second part focused the opinion of survey stakeholders' mainly industrial community with regards to the incorporation of cloud services and platforms for data warehousing and processing in Moroccan manufactories.

\section{Results and discussion}

\subsection{Survey results and analysis}

\subsubsection{Industry 4.0 perception within Moroccan context}

The most selected response with a percentage of $33 \%$ linked industry 4.0 definition to the development within industry of artificial intelligence, and Industrial Internet of Things IloT. This perception is reinforced by the government increasing interests towards the development of these two aspects of industry 4.0, through the promotion of projects and initiatives that reinforce their integration within Morocco, and by survey results that were launched with the purpose of analyzing industry 4.0 integration within Morocco and its potential opportunities [44] (Fig. 6).
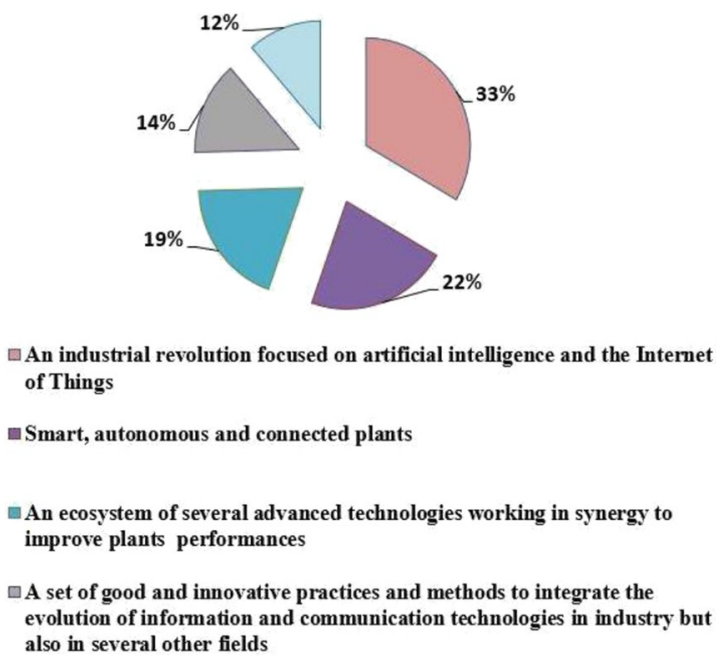

Fig. 6 Industry 4.0 definition

\subsubsection{Industry 4.0 applications}

As we can notice from the chart transport and intelligent mobility has the highest percentage with $30 \%$ according the study sample evaluation. Whereas the potential applications of industry 4.0 in the field of sustainable development ranks last with $9 \%$. Through this classification we can conclude on the upward necessity of the Moroccan context with regard to urban traffic management which may offer an interesting development opportunity for digital twin technology especially that this is a field that is little explored by literature and existing digital twins' applications. E-Learning which is a widespread field of application of digital twins ranked second with $23 \%$ which once again demonstrates the need to explore the potentiality of the concept in a Moroccan context especially that Moroccan government and institutions gives a great importance to the promotion and integration of advanced technological solutions in the field of education. In this sense a lot of platforms and Moroccan MOOCs were created by universities to support this axe [45], and recently Morocco has inaugurated in Benguerir its first institution for the integration of augmented and virtual reality in the educational ecosystem. Two other fields were highlighted by the sample and can give a lot of opportunities to digital twins in relationship to Moroccan context needs. The first filed is smart agriculture which is a scientific subject of concern

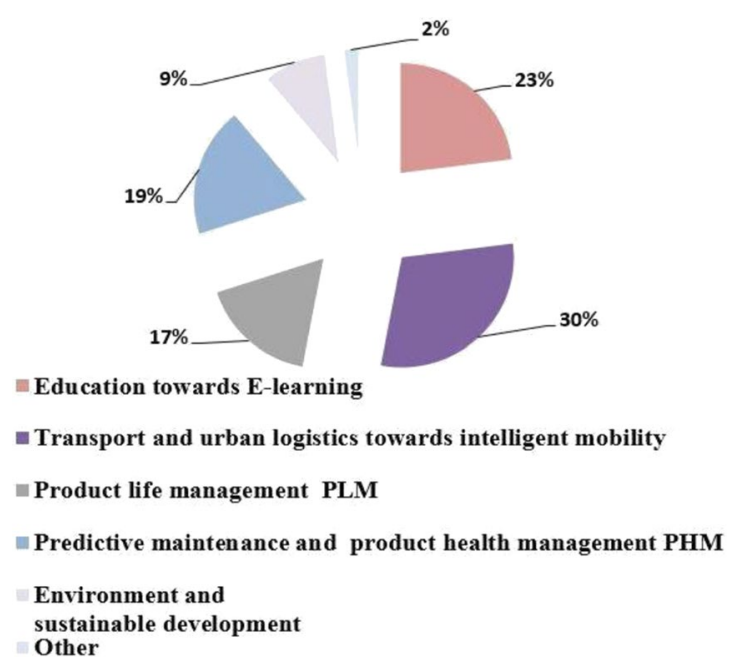

Fig. 7 Industry 4.0 fields of applications 
for Moroccan researchers and industrialists especially with its leading companies for example OCP group. The second field is public administrations and services that are an important field for Moroccan digital transformation as stated in the previous section (Fig. 7).

\subsubsection{Technologies and concepts}

The main purpose behind this query was to evaluate the potential of digital twins among the solutions and technologies proposed by Industry-4.0. The classification of the different solutions showed once again the great interest that the Moroccan context has in the development of IA

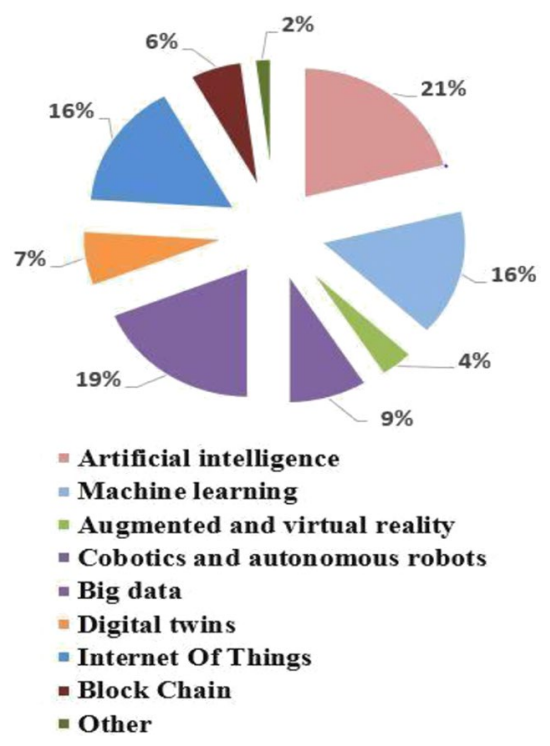

Fig. 8 Industry 4.0 ecosystem

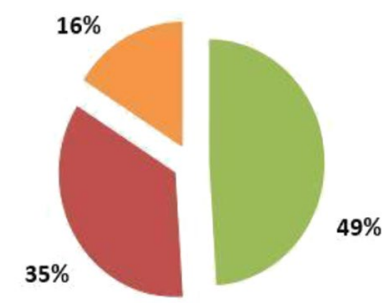

\footnotetext{
A virtual representation of a real system that allows a real time visualization of the system's operation and performance

A dynamic representation of a complex system in a virtual environment with advanced computing and processing capabilities

idvanced simulation technology
}

Fig. 9 Digital twin perception and definition which records the highest number with $21 \%$. These results reinforce the results concluded by the national surveys made in the field of industry 4.0. The digital twins according to the survey sample is classified into a ranking of 7 . This once again justifies the need to clearly identify the obstacles that could hinder the deployment of the solution despite its great potential regarding the problems and needs of the context. Figure 8 represents the result of this category within industry 4.0 frameworks, and Fig. 11 within digital twin development and deployment framework.

\subsubsection{Digital twins' perception}

This section of the survey aimed to identify the perception of the context in regards to the notion of digital twins, and the definitions concluded through the state of the art [46]. Through the responses we were able to gather from the selected sample we could notice that for many of them the notion is still an abstraction, and for many industrial the notion was still unknown. Their responses were based on a first intuition of what they define as a twin of a physical system under fourth industrial revolution concepts and applications which counts among them real time monitoring. Figure 9 introduces the different definitions and the survey results concerning sample perception of digital twin concept.

\subsubsection{Requirements and deployment criteria}

Though the state of the art on digital twins we were able to define some of digital twins' evaluation criteria. This part aimed at reinforcing these criteria and selects from them the most important ones for digital twins' implementation within Moroccan plants according to the targeted communities throughout the survey. The results showed that the first and most important criteria while choosing a digital twin solution is adaptability and interoperability with current organization systems and this is the same observation made by many studies launched for the analysis of Morocco readiness to integrate industry 4.0. The second one is existence of national and international certifications and laws organizing concept deployment, and the investment in material and human resources in comparison with the return on investment of the project as a whole. As a result, we concluded on four categories of criteria that should be detailed for the choice of the appropriate digital twin implementation architectures and technologies. The four categories are solution ergonomic, efficiency, conformity, and interoperability. Solution ergonomic which is related to user's interaction with the twin developed platform, and human capabilities needs, and requirements was highlighted by a lot of Moroccan studies 


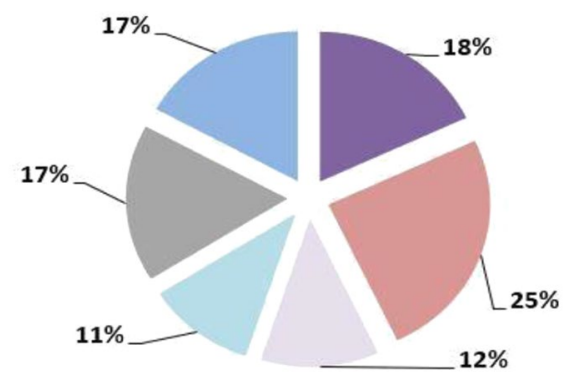

wesistance to change of employees

High development and deployment costs

The return on investment is sustainable in the long term

The need to train or recruit new employees

The lack of mastery of these new concepts

Eecurity and confidentiality risks

Fig. 10 Digital twin deployment challenges and threats

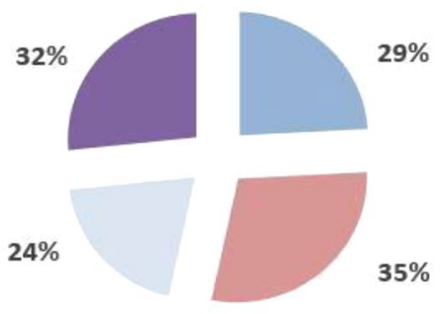

- Big data

- Internet of Thing IoT

Augmented reality and virtual reality

- Cloud computing

Fig. 11 Digital twin within industry 4.0 ecosystem

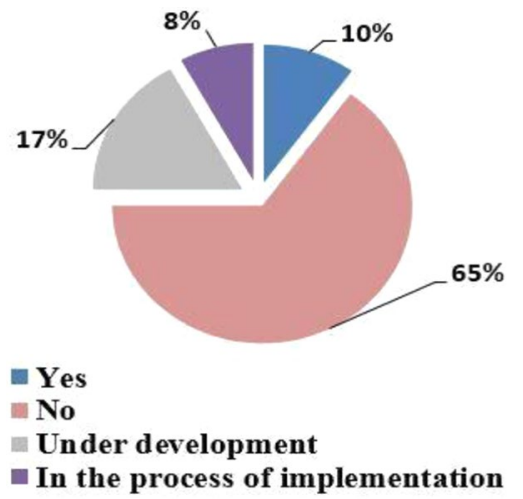

Fig. 12 Digital twin deployment and development within Morocco and international reports on Moroccan digital transformation. Digital twin interoperability with legacy systems and industry 4.0 technologies interoperability in general are subject of studies for a lot of research communities and were stated in some of Morocco scientific published research in recent years. These categories can be detailed further according to companies' specific context in order to evaluate digital twins' development road map and usage maturity evaluation (Fig. 10).

\subsubsection{Digital twins and industry 4.0 concepts}

Figure 11 represents the results for digital twins development and deployment project in relationship with different industry 4.0 concepts, and Fig. 12 represents the response to the question related to digital twins implementation within morocco. The responses about the technology adapted for the sample that chose yes for the majority of the sample interviewed proved that there is no yet a clear definition and perception of digital twins technologies among Moroccan industrials. Some of the companies that propose digital twins' technologies have their branch within Morocco such as Siemens Gamesa, Schneider Electric, HoneyWell, Microsoft and International Business Machines Corporation IBM.

This can represent a great opportunity and advantage for the concept development in the industrial filed as these companies already through years acquired a feedback of constraints and requirements concerning advanced technologies implementation within Moroccan industrial environment.

\subsubsection{Implementation threats and obstacles}

This part of the study discussed obstacles and contextual risks that could hinder the deployment of digital twins. The results of this category are represented in Fig. 10.

Survey results showed that the first hurdle with $25 \%$ is digital twins' development and deployment costs. The second is employee's resistance to the integration of new technologies with $18 \%$. The third ones are technologies lack of mastery, and security and confidentiality risks, then we find the return of investment in the long term. And finally, the need to train or recruit new employees with $11 \%$. Thus, we can group all these risks under three main categories, risks related to the human factor this risk was also highlighted by Germany report on Morocco readiness to integrate industry 4.0, security factor and finally the economic and financial factors. Thus, the efficient development and deployment of digital twins' solution will have to go through the evaluation of the defined risks categories and the establishment of an action plan to reduce their criticality. 


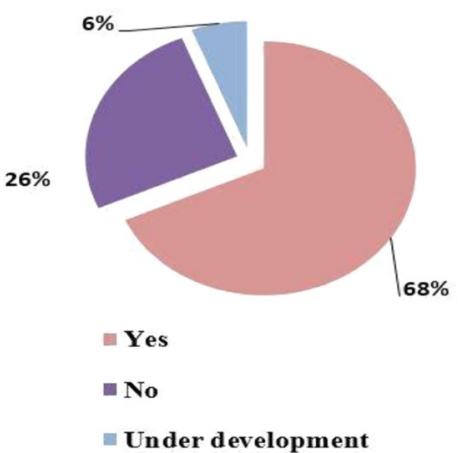

Fig. 13 Software infrastructure for digital twin implementation ERP

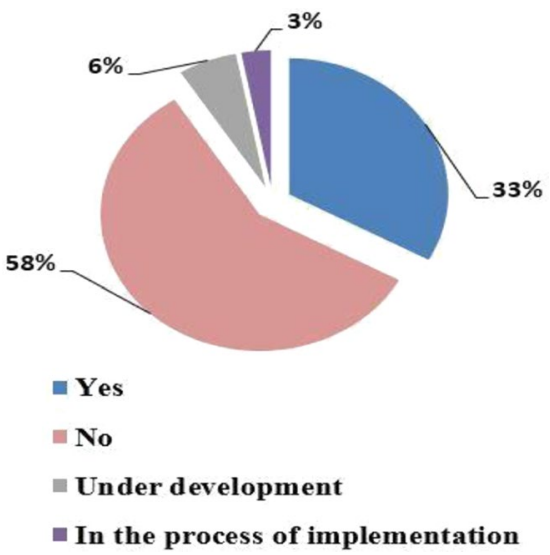

Fig. 14 Software infrastructure for digital twin implementation MES systems

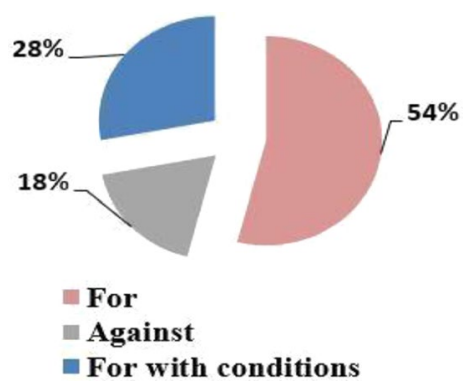

Fig. 15 Cloud computing perception and endorsement

\subsubsection{Physical environment factors and constraints}

As we noticed from the results of question 6 adaptability and interoperability with existing systems are crucial parameter within the process of developing and implementing digital twins within Moroccan industrial plants. Thus, we proposed in reference to the state of the art established before a set of questions that deal with these

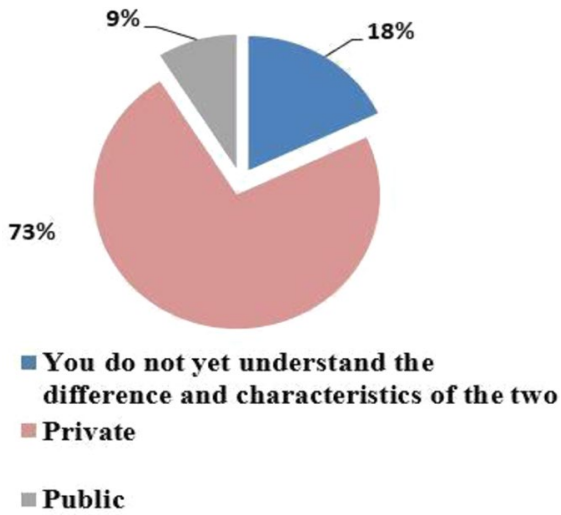

Fig. 16 Private and public cloud

aspects of digital twins' development and deployment project. The survey questions were about industry community satisfaction with regards to existing storage and monitoring systems mainly Enterprise Resource planning systems ERP, Manufacturing Execution systems MES, and cloud computing. The results represented through Figs. 13, 14,15 and 16 respectively showed that the majority of enterprises targeted through the survey with a percentage of $69 \%$ has their own developed ERP system and $58 \%$ doesn't have an MES system which can be an obstacle for digital twins as it has to be integrated within the actual architecture properly in order to record a high efficiency. Concerning cloud computing concepts and integration $54 \%$ of the survey sample agreed on adapting cloud storage services and $18 \%$ are against it whereas the majority agreed regards to some conditions that are security, data confidentiality and data governance.

\subsection{Synthesis and discussion}

Works on this first case study, which concerned Moroccan context, allowed us to identify other technical and socioeconomical aspects that interact for the development of the concept and its perception in an emerging industrial context. The first aspect that we were able to conclude from the analysis of the survey first section is developed digital twin solution interoperability with regard firstly to hosting environment hardware and software infrastructures and secondly with relationship to its interaction with its potential users and stakeholders. It is compulsory for digital twins to meet its hosting environment needs and requirements; creating a proof of concept framework; and highlighting the added value of digital twins throughout different industries and domains supply chain is a key enabler for the concept adoption and mastering. Survey results revealed a lot of opportunities for digital twins 
within Morocco especially according to the interviewed communities' opportunities associated with internet of things technologies and big data.

Exploring these opportunities and acquiring experience from the deployment of different solutions and architectures can bring up a lot of other possibilities that will contribute to the enhancement of digital twins' field. The second aspect that we were able to identify from our analysis of the results and discussions is the combination of digital twin's and artificial intelligence. Morocco has done a lot of effort recently to raise awareness on the relevance of artificial intelligence and the different opportunities it can offer for the development of the country not only from an industrial point of view but also Exploring these opportunities and acquiring experience from the deployment of different solutions and architectures can bring up a lot of other possibilities that will contribute to the enhancement of digital twins' field. The second aspect that we were able to identify from our analysis of the results and discussions is the combination of digital twin's and artificial intelligence. Morocco has done a lot of effort recently to raise awareness on the relevance of artificial intelligence and the different opportunities it can offer for the development of the country not only from an industrial point of view but also from a social point of view to improve citizens' quality of life. Combining digital twins and artificial intelligence for tackling countries problematics in different fields public services, education, with a lot of efforts and in-depth researches healthcare and priority urban mobility as showcased by the survey results can help to enhance both fields integration into Moroccan context. In 2018 digital twins were placed by Gartner Hype cycle for emerging technologies in the category of technologies within the peak of inflated expectations and today research communities that works on the subject are working in order to carries the concept through the next level. This next level will have to encompass real systems mirroring which is one of the main functions of digital twin to more advanced features that enables digital twins to add a layer of intelligence and autonomy to complex systems development. Throughout our analysis in regards with the different sections of the survey a lot of challenges come to hinder digital twins shift towards advanced levels and resulted on its consideration as a technology that attained its peak of inflated expectations. Some of these challenges are related to other domains such as data science, industrial internet of things, and automation deployment with the fusion of information technologies.

SN Applied Sciences

A SPRINGER NATURE journal

\section{Concluding remarks and future works}

The first section of the questionnaire focused on Moroccan scientific and industrial communities' perception of Industry 4.0, its concepts and technologies and the identification of its current state and its impact in relationship to the different problematics encountered by Morocco currently. The second section centered on the concept of digital twins primarily in relation to industry 4.0 ecosystem and secondly with regard to the opportunities offered for the deployment of the concept throughout Morocco. Finally, the last section addressed a relevant aspect for the deployment of digital twins which is the level of maturity of the country's IT infrastructure. The analysis of the results obtained showed first of all in relationship to the Moroccan context the motivation of the country to make great strides in the world of digitization, and the commitment of its various actors and institutions to meet the various technical and contextual requirements that could relate to digital twins development and its integration within industrial plants. Secondly with regards to the field of digital twins it constitutes a relevant experience feedback on the opportunities and challenges that can meet the concept deployment requirements on a developing country and emerging industry. Through the state of the art developed in relationship to the concept and presented in the first section we could notice that a significant number of researches related to digital twins before industry 4.0 dealt with issues specific to the development of digital twin as such. For example digital twins product specific requirements such as its reliability for representing its compatriot in the field, its efficiency, its scope of communication and interconnections, its potential of application as well as its overall perception and understanding throughout proposed definitions, and interactions with other concepts that could lighten the complex process of its conception, and more generally computational capacities necessary for its software infrastructure building in order to represent faithfully and with real-time manner the functioning of a complex physical system whom functioning is linked to several other problems involving mechanics, electrical engineering and automation. To tackle these challenges digital twin proposed deployment architecture will have to be both adaptive and generic. Taking into consideration this conclusion our future works will focus on the development of a holistic digital twins' architecture, and a generic digital twin maturity assessment model.

Acknowledgements This research was supported by Mohammed VI Polytechnic University of Benguerir, Morocco and OCP group. We thank our colleagues from university who provided insight and expertise that greatly assisted the research. We thank our colleagues from university who provided insight and expertise that greatly assisted the research. 


\section{Compliance with ethical standards}

Conflict of interest The authors declare that they have no conflict of interest.

Ethical approval This research study was concluded as part of the projects launched by Polytechnic University of Mohammed VI of Benguerir UM6P in partnership with Research Foundation for Development and Innovation in Science and Engineering of Casablanca FRDISI for the digital transformation of Morocco Cherifien Phosphate Office OCP. The survey data are anonymized.

\section{References}

1. Xu LD, Xu EL, Li L (2018) Industry 4.0: state of the art and future trends. Int J Prod Res 56(8):2941-2962

2. V. fr-Agence de production digitale (2019) Vision stratégique 2016-2020. [En ligne]. Disponible sur: http://www.ompic.org. $\mathrm{ma} / \mathrm{fr} /$ content/vision-strategique-2016-2020. Consult 09 Nov 2019

3. Catalogue des projets| eGov Maroc-Programme e-Gouvernement du plan Maroc Numeric. [En ligne]. Disponible sur: http://www.egov.ma/fr/catalogue-des-projets. Consult 27 Oct 2019

4. El Saddik A (2018) Digital twins: the convergence of multimedia technologies. IEEE Multimedia 25(2):87-92

5. Shao G, Kibira D (2018) Digital manufacturing: requirements and challenges for implementing digital surrogates. In: 2018 Winter simulation conference (WSC). Gothenburg, Sweden, pp 1226-1237

6. Durão LFCS, Haag S, Anderl R, Schützer K, Zancul E (2018) Digital twin requirements in the context of industry 4.0. In: Chiabert $P$, Bouras A, Noël F, Ríos J (eds) Product lifecycle management to support industry 4.0, vol 540. Springer, Cham, pp 204-214

7. Tao F, Zhang H, Liu A, Nee AYC (2019) Digital twin in industry: state-of-the-art. IEEE Trans Ind Inform 15(4):2405-2415

8. Grieves MW (2005) Product lifecycle management: the new paradigm for enterprises. Int J Prod Dev 2(1/2):71

9. Webcast: Dr. Michael grieves-digital twin: manufacturing excellence through virtual factory replication. [En ligne]. Disponible sur: http://www.apriso.com/library/video/dr_griev es_digital_twin_webcast_en.php. Consult 06 Avr 2019

10. Grieves M, Vickers J (2017) Digital twin: mitigating unpredictable, undesirable emergent behavior in complex systems. In: Kahlen F-J, Flumerfelt S, Alves A (eds) Transdisciplinary perspectives on complex systems. Springer, Cham, pp 85-113

11. Glaessgen E, Stargel D (2012) The digital twin paradigm for future NASA and U.S. air force vehicles. In: 53rd AIAA/ASME/ ASCE/AHS/ASC structures, structural dynamics and materials conference $<\mathrm{BR}>20$ th $\mathrm{AIAA} / \mathrm{ASME} / \mathrm{AHS}$ adaptive structures conference $<B R>14$ th AIAA, Honolulu, Hawaii

12. Kraft EM (2016) The air force digital thread/digital twin-life cycle integration and use of computational and experimental knowledge. In: 54th AIAA aerospace sciences meeting. San Diego, California, USA

13. West TD, Blackburn M (2017) Is digital thread/digital twin affordable? A systemic assessment of the cost of DoD's latest manhattan project. Procedia Comput Sci 114:47-56

14. Aivaliotis P, Georgoulias K, Alexopoulos K (2019) Using digital twin for maintenance applications in manufacturing: state of the art and gap analysis. In: 2019 IEEE international conference on engineering, technology and innovation (ICE/ ITMC). Valbonne Sophia-Antipolis, France, pp 1-5

15. Gao Y, Lv H, Hou Y, Liu J, Xu W (2019) Real-time modeling and simulation method of digital twin production line. In: 2019 IEEE 8th joint international information technology and artificial intelligence conference (ITAIC). Chongqing, China, pp 1639-1642

16. Caputo F, Greco A, Fera M, Macchiaroli R (2019) Digital twins to enhance the integration of ergonomics in the workplace design. Int J Ind Ergon 71:20-31

17. David J, Lobov A, Lanz M (2019) Attaining learning objectives by ontological reasoning using digital twins. Procedia Manuf 31:349-355

18. Schleich B, Anwer N, Mathieu L, Wartzack S (2017) Shaping the digital twin for design and production engineering. CIRP Ann 66(1):141-144

19. Zhou M, Yan J, Feng D (2019) Digital twin framework and its application to power grid online analysis. CSEE J Power Energy Syst 5(3):391-398

20. Lutze R (2019) Digital twins in eHealth: prospects and challenges focussing on information management. In: 2019 IEEE international conference on engineering, technology and innovation (ICE/ITMC). Valbonne Sophia-Antipolis, France, pp 1-9

21. Redelinghuys A, Basson A, Kruger K (2019) A six-layer digital twin architecture for a manufacturing cell. In: Borangiu T, Trentesaux D, Thomas A, Cavalieri S (eds) Service orientation in holonic and multi-agent manufacturing, vol 803. Springer, Cham, pp 412-423

22. Tao F, Cheng J, Qi Q, Zhang M, Zhang H, Sui F (2018) Digital twindriven product design, manufacturing and service with big data. Int J Adv Manuf Technol 94(9-12):3563-3576

23. Tao F, Qi Q, Wang L, Nee AYC (2019) Digital Twins and cyberphysical systems toward smart manufacturing and industry 4.0: correlation and comparison. Engineering 5(4):653-661

24. Lazazzara A, Ricciardi F, Za S (eds) (2020) Exploring digital ecosystems: organizational and human challenges, vol 33. Springer, Cham

25. \#digitalfikra : Le brainstorming national en matière de digital est en marche !. [En ligne]. Disponible sur: https://industries.ma/ digitalfikra-le-brainstorming-national-en-matiere-de-digitalest-en-marche/. Consult 28 Mars 2019

26. Laadem M (2017) E-learning integration in higher education: focus on moroccan departments of english. PIJTEL 1(2)

27. Hajar EM, Abdelghani C (2017) Exploring the emergence of a new smart city model: case analysis of the Moroccan urbanization. In: 2017 1st international conference on intelligent systems and information management (ICISIM). Aurangabad, pp 293-299

28. Hereu J (2018) 1. Smart city expo Casablanca, ed. 2018 2. Villes à vivre et innovation Citoyenne 3. Temps forts a. Discours 1 la smart city en tant que projet. p 50

29. Sbai S, Louhdi MRC, Behja H, El Moukhtar Z, Rabab C (2019) Using reverse engineering for building ontologies with deeper taxonomies from relational databases. J Softw 14(3):138-145

30. Khtira R, Elasri B, Rhanoui M (2017) From data to big data: Moroccan public sector. In: Proceedings of the 2 nd international conference on big data, cloud and applications-BDCA'17, Tetouan, Morocco, pp 1-6

31. Mahjoubi AE, Mazri T, Hmina N (2017) First Africa and Morocco NB-IoT experimental results and deployment scenario: new approach to improve main $5 \mathrm{G}$ KPIs for smart water management. In: Proceedings of the mediterranean symposium on smart city application-SCAMS'17. Tangier, Morocco, pp 1-6

32. Belkhala S, Benhadou S, Boukhdir K, Medromi H (2019) Smart parking architecture based on multi agent system. Int J Adv 
Comput Sci Appl. https://doi.org/10.14569/IJACSA.2019.01003 49

33. Appel à projet $\mid$ Ministère de l'Industrie, du Commerce et de I'Économie Verte et Numérique. [En ligne]. Disponible sur: http://www.mcinet.gov.ma/fr/content/appel-a-projet. Consult 11 Nov 2019

34. Khaouja I, Rahhal I, Elouali M, Mezzour G, Kassou I, Carley KM (2018) Analyzing the needs of the offshore sector in Morocco by mining job ads. In: 2018 IEEE global engineering education conference (EDUCON). Tenerife, pp 1380-1388

35. Gartner survey reveals digital twins are entering mainstream use. Gartner. [En ligne]. Disponible sur: https://www.gartn er.com/en/newsroom/press-releases/2019-02-20-gartner-surve y-reveals-digital-twins-are-entering-mai. Consult 18 Mai 2019

36. West TD, Pyster A (2015) Untangling the digital thread: the challenge and promise of model-based engineering in defense acquisition. Insight 18(2):45-55

37. Ebrahimi A (2019) Challenges of developing a digital twin model of renewable energy generators. In: 2019 IEEE 28th international symposium on industrial electronics (ISIE). Vancouver, BC, Canada, pp 1059-1066

38. Borth M, Verriet J, Muller G (2019) Digital twin strategies for SoS 4 challenges and 4 architecture setups for digital twins of SoS. In 2019 14th Annual conference system of systems engineering (SoSE). Anchorage, AK, USA, pp 164-169

39. Sbaglia L, Giberti H, Silvestri $M$ (2019) The cyber-physical systems within the industry 4.0 framework. In: Carbone G, Gasparetto A (eds) Advances in Italian mechanism science, vol 68. Springer, Cham, pp 415-423
40. Bakkari M, Khatory A. Industry 4.0: strategy for more sustainable industrial development in SMEs. p 9

41. Home-Morocco data portal. Knoema. [En ligne]. Disponible sur: http://morocco.opendataforafrica.org/. Consult 08 Nov 2019

42. Livre Blanc: La Transformation Digitale Au Maroc.-AUSIM MAROC. [Online]. Available: http://www.ausimaroc.com/livre -blanc-la-transformation-digitale-au-maroc/. Accessed 29 Dec 2019

43. Digital Twin towards a meaningful framework-Arup. [Online]. Available: https://www.arup.com/perspectives/publications/ research/section/digital-twin-towards-a-meaningful-frame work. Accessed 25 Dec 2019

44. El Hamdi S, Oudani M, Abouabdellah A (2020) Morocco's readiness to industry 4.0. In: Bouhlel MS, Rovetta S (eds) Proceedings of the 8th international conference on sciences of electronics, technologies of information and telecommunications (SETIT'18). Springer, Cham, vol 146, pp 463-472

45. J UM5MOOC. [En ligne]. Disponible sur: http://mooc.um5.ac.ma/. Consult 09 Nov 2019

46. Chinesta F, Cueto E, Abisset-Chavanne E et al (2020) Virtual, digital and hybrid twins: a new paradigm in data-based engineering and engineered data. Arch Comput Methods Eng 27:105-134. https://doi.org/10.1007/s11831-018-9301-4

Publisher's Note Springer Nature remains neutral with regard to jurisdictional claims in published maps and institutional affiliations. 